\title{
Therapeutic Plasmapheresis: Seven Year Experience of an Intensive Care Unit in Portugal
}

\author{
Plasmaferese Terapêutica: Experiência de Sete Anos de um \\ Serviço de Medicina Intensiva em Portugal
}

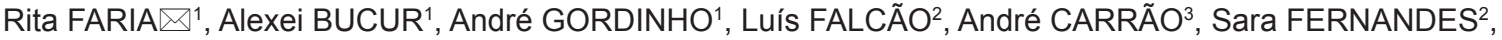 \\ João Pedro COLAÇO ${ }^{4}$, Carlos MENESES-OLIVEIRA ${ }^{1}$, António MESSIAS ${ }^{4}$
}

Acta Med Port 2022 Mar;35(3):176-183 - https://doi.org/10.20344/amp.14266

\section{ABSTRACT}

Introduction: Therapeutic plasmapheresis is a therapeutic procedure in which the patient's blood is passed through a medical device which separates out plasma from other components of blood. The plasma is removed and replaced with a replacement solution. Studies on the use of plasmapheresis in critically ill patients are scarce. The aim of this study was to review all therapeutic plasmapheresis sessions carried out in the Hospital Beatriz Ângelo intensive care unit.

Material and Methods: An observational retrospective study was conducted between April 2012 and March 2019. All patients who underwent therapeutic plasmapheresis in the intensive care unit were included, and plasmapheresis sessions held outside the intensive care unit were excluded.

Results: Of 46 patients, $63 \%$ were men $(n=29)$, with a median age of 53 years. The most frequent diagnoses were hypertriglyceridemia-induced pancreatitis, vasculitis, autoimmune haemolytic anaemia, and atypical haemolytic-uremic syndrome. A total of 198 plasmapheresis sessions were carried out in the intensive care unit. Most of the used replacement solutions were fresh frozen plasma (34.4\%), albumin/crystalloid (24.2\%), and albumin/fresh frozen plasma (19.2\%). The most common complications were hydroelectrolytic changes $(84 ; 42.4 \%)$ and coagulation disorders/thrombocytopenia $(65 ; 32.8 \%)$. There was no need to interrupt any plasmapheresis session due to complications related to the patient.

Conclusion: Therapeutic plasmapheresis is a complex technique that requires specific training. The indications are diverse, and some are not consensual. Complications were frequent, but they did not increase morbidity.

Keywords: Critical IIIness/therapy; Plasma Exchange/methods; Plasmapheresis/adverse effects; Plasmapheresis/methods; Plasmapheresis /therapeutic use

\section{RESUMO}

Introdução: A plasmaferese terapêutica é um procedimento em que o sangue passa por um circuito extracorpóreo que separa o plasma dos outros componentes do sangue. O plasma removido é substituído por soluções de reposição. Os estudos sobre a utilização de plasmaferese terapêutica no doente crítico são escassos. O objetivo do estudo foi rever todas as sessões de plasmaferese realizadas no serviço de Medicina Intensiva do Hospital Beatriz Ângelo.

Material e Métodos: Estudo observacional retrospetivo de todos os doentes admitidos no serviço de Medicina Intensiva entre abril de 2012 e março de 2019. Foram selecionados os doentes submetidos a plasmaferese e excluídas as sessões realizadas fora do serviço de Medicina Intensiva.

Resultados: No período de estudo foram incluídos 46 doentes. A maioria eram homens $(n=29 ; 63 \%$ ) com uma idade mediana de 53 anos. Os diagnósticos mais frequentes foram pancreatite secundária a hipertrigliceridemia, vasculite, anemia hemolítica autoimune e síndrome hemolítica urémica atípica. Foram realizadas 198 sessões de plasmaferese no serviço de Medicina Intensiva. As soluções de substituição mais utilizadas foram plasma fresco congelado $(34,4 \%)$, albumina/cristalóide $(24,2 \%)$ e albumina/plasma (19,2\%). As complicações mais comuns foram alterações hidroeletrolíticas (84; 42,4\%), e distúrbios da coagulação/plaquetas (65; 32,8\%). Em nenhum dos casos a técnica teve que ser interrompida por complicações relacionadas com o doente.

Conclusão: A plasmafere terapêutica é uma técnica complexa que requer treino específico. As indicações são diversas e algumas não consensuais. As complicações foram frequentes, mas não condicionaram morbilidade associada.

Palavras-chave: Estado Crítico/tratamento; Plasmafere/efeitos adversos; Plasmafere/métodos; Plasmafere/uso terapêutico; Troca Plasmática/métodos

\section{INTRODUCTION}

Therapeutic plasmapheresis (PX) is a therapeutic procedure in which blood of the patient passes through a medical device which separates out plasma from other components of blood in order to remove high molecular weight compounds. These compounds may be antibodies, toxins, and other disease specific molecules. The plasma is removed and replaced with a replacement solution such as colloid solution (e.g., albumin and/or plasma) or a combination of crystalloid/colloid solution. ${ }^{1}$ The body's inability to clear these molecules, as well as renal replacement techniques increase the need for PX in order to change the course of the disease, thus reducing its morbidity and mortality.

1. Intensive Care Department. Hospital Beatriz Ângelo. Loures. Portugal.

2. Nephrology Department. Hospital Beatriz Ângelo. Loures. Portugal.

3. Anaesthesiology Department. Hospital Beatriz Ângelo. Loures. Portugal.

4. Intensive Care Department. Hospital da Luz. Lisboa. Portugal.

$\triangle$ Autor correspondente: Rita Faria. faria.rita.fr@gmail.com

Recebido: 04 de junho de 2020 - Aceite: 11 de maio de 2021 - First published: 20 de agosto de 2021 - Online issue published: 02 de março de 2022

Copyright $\odot$ Ordem dos Médicos 2022 
The plasma-separation methods can be centrifugation or filtration. Centrifugation was the first method used for PX and relies on the variation in the specific gravity of blood components These systems are often large and complicated and suffer from contamination of the separated plasma with platelets and other cellular components. This method has a high plasma extraction ratio $(80 \%)$, so a low blood flow rate is required, which can be achieved by peripheral venous access (up to $80 \mathrm{~mL} / \mathrm{min}$ ). Filtration is a membrane-based separation method, which relies on particle size. With advances in membrane technology, it has become more biocompatible, safer, and more adaptable to conventional haemodialysis and hemofiltration machines. The membranes used for PX have significantly larger pores $(0.2-0.3 \mu \mathrm{m})$ than the membranes used in hemofiltration, allowing macromolecules, but not cellular components, to convectively cross the membrane. The advantages of this method are operational simplicity, lower cost, more reliability, and potentially no loss of cellular components as can be seen with centrifuge-based plasma removal. However, as the plasma extraction ratio is lower, it requires a higher blood flow rate $(50-200 \mathrm{~mL} / \mathrm{min})$ to achieve the same plasma separation. In order to do so, a double lumen central venous catheter must be inserted, which has some specific complications. $^{2}$

At our hospital, both in the intensive care unit (ICU) and the Medical Day Hospital (MDH), we apply the filtration method, using the haemodialysis monitor Multifiltrate (Fresenius ${ }^{\circledR}$ ) and the filter PlasmaFlux (PSU 2S). Plasma is removed and replaced with a solution that can be fresh frozen plasma (FFP), albumin, crystalloid, or combinations of these.

There are scarce published data about the applicability and safety of PX in a critical care environment, despite the higher probability of complications in this group of patients. ${ }^{3-6}$

According to the latest guidelines of the American Society for Apheresis (ASFA) 2019, indications for PX may be divided into categories, according to the level of scientific evidence. Category I includes indications for PX as the firstline therapeutic option, and category II includes indications for PX as the second-line therapeutic option. In categories III-IV, the benefit has not been well established. ${ }^{1}$

PX has been carried out in our ICU since its opening in 2012 , but there has never been a systematic analysis of the procedure. For that reason, in order to improve daily clinical practice, and because studies on the use of PX in critically ill patients are scarce, ${ }^{7-10}$ we developed this study. The aim of this study was to review all PX sessions that were held at the ICU of Beatriz Ângelo Hospital (HBA), including the total number of sessions, diagnosis and indication for $\mathrm{PX}$, characteristics of each session, and associated complications.

\section{MATERIAL AND METHODS}

This single-centre, retrospective observational study was conducted at HBA's ICU (Loures, Portugal). This is a type-C ICU consisting of 22 beds (levels 2 and 3). Of all the patients admitted to the ICU in the period between April 2012 and March 2019, those undergoing PX were selected, and sessions held outside the ICU were excluded. Data were collected from clinical records and recorded in a specific database. The collected data included the following: demographic data, diagnosis and indication for PX, total number of PX sessions, number of sessions per patient and their frequency, characteristics of each PX session, including replacement solution, volemic replacement, type of anticoagulation, complications associated with PX session, need for invasive mechanical ventilation (IMV) and renal replacement therapy (RRT), length of stay (LOS) in the ICU and in the hospital, and mortality in the ICU and in the hospital.

The Ethics Committee of HBA approved the study. Informed consent was waived given the characteristics of the study.

\section{Statistics}

The pseudoanonimized database was created using the program FileMaker Pro Advanced version 17.0.4. Statistical analysis was performed using Excel version 16.28.

Categorical and discrete variables are presented as frequency or number and percentage (\%). Continuous variables with normal distribution are expressed as mean \pm standard deviation and continuous variables without normal distribution as median and interquartile range (Q1 - Q3).

\section{RESULTS}

The retrospective analysis identified 46 patients for inclusion $[0.4 \%$ of all patients admitted to the ICU $(n=11232)$ and $0.6 \%$ of patients admitted at level $3(n=7518)]$. Most patients were men $(29 ; 63 \%)$, and $37 \%$ were women $(n=$ 17 ) with a median age of 53 years $(43-68)$, median body mass index of $26(23-29)$, and median APACHE score of $13(6-18)$. The total number of PX sessions performed during patients' ICU stay was 227. Of these, 29 sessions were excluded from the analysis as they were held outside the ICU at the MDH Therefore, we only analysed the 198 PX sessions performed by the ICU staff. Thirteen patients (28.2\%) maintained the need for PX after discharge from the $\mathrm{UCl}$.

\section{Diagnosis and indication}

The most frequent initial diagnoses with an indication for PX included the following: hypertriglyceridemia-induced pancreatitis $(13 ; 28.2 \%)$, vasculitis $(8 ; 17.4 \%)$, autoimmune haemolytic anaemia $(5 ; 10.9 \%)$, atypical haemolytic-uremic syndrome (aHUS) $(5 ; 10.9 \%)$, and Guillain-Barré syndrome (GBS) $(4 ; 8.7 \%)$ (Fig. 1).

The initial diagnosis was confirmed in 40 patients (87\%). It was confirmed before initiating PX in $63 \%(n=29)$. However, in 17 patients (37\%), PX was initiated before the definitive diagnosis due to clinical severity and a high degree of clinical suspicion. In the six cases in which the initial diagnosis was not confirmed, two maintained an indication for plasmapheresis. 
Initial diagnosis

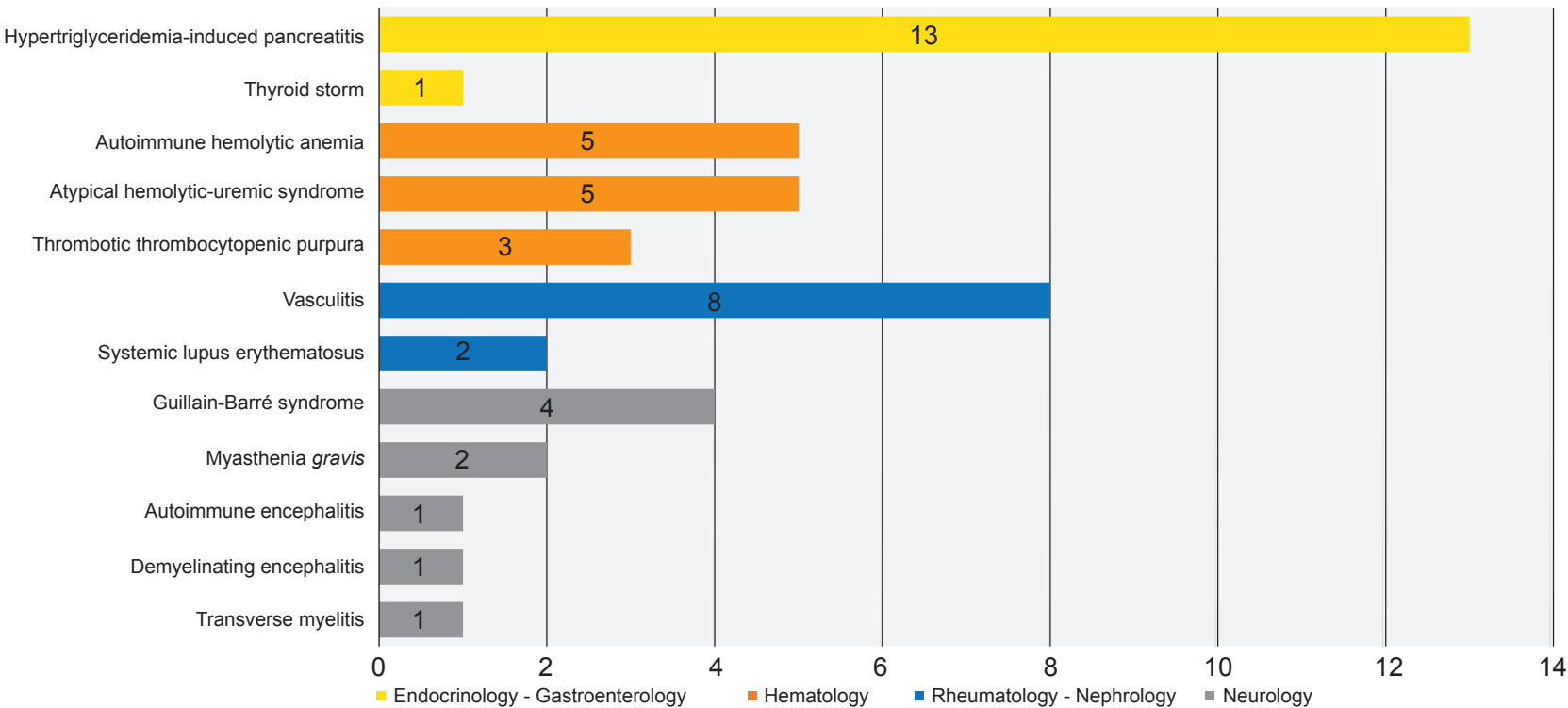

Figure 1 - Distribution of the number of patients requiring therapeutic plasmapheresis during admission to the intensive care unit, according to the initial diagnosis

As for to the initial diagnosis, the main indications for PX were triglycerides over $1000 \mathrm{mg} / \mathrm{dL}$ in hypertriglyceridemiainduced pancreatitis $(13 ; 28.3 \%)$, clinical severity in different conditions $(13 ; 28.3 \%)$, as a first-line therapeutic option $(8 ; 17.4 \%)$, diffuse alveolar haemorrhage $(7 ; 15.2 \%)$, refractoriness to the first therapeutic line $(4 ; 8.7 \%)$ and dialysis dependence $(1 ; 2.1 \%)$ (Table 1 ).

\section{Plasmapheresis and associated therapy}

Plasmapheresis was used as an isolated therapy in 19 patients $(41.3 \%)$, associated with corticosteroids or other type of immunosuppression in 17 patients (36.9\%), with immunoglobulin in five patients $(10.9 \%)$ and in combination with all aforementioned therapies in five patients (10.9\%).

\section{Organ support: renal replacement therapy and invasive mechanical ventilation}

Regarding the need for organ support, most patients did not require IMV $(29 ; 63 \%)$. In the group of patients undergoing IMV $(17 ; 37 \%)$, the most common diagnoses were GBS $(4 ; 23.5 \%)$ and vasculitis $(4 ; 23.5 \%)$. RRT was required in 17 patients $(37 \%)$. In this group, RRT was intermittent in

Table 1 - Indication for therapeutic plasmapheresis, according to the diagnosis

\begin{tabular}{|c|c|c|c|}
\hline Disease & Indication & Category & $\begin{array}{c}\mathbf{n} \\
(46)\end{array}$ \\
\hline Hypertriglyceridemia-induced pancreatitis & Triglyceridemia > 1000 mg/dL & III & 13 \\
\hline \multirow{2}{*}{ Vasculitis } & Diffuse alveolar hemorrhage & I & 7 \\
\hline & Dialysis dependence & I & 1 \\
\hline $\begin{array}{l}\text { Atypical hemolytic-uremic syndrome } \\
\text { (thrombotic microangiopathy) }\end{array}$ & Severe & $\begin{array}{c}\text { I - III } \\
\text { (according to etiology) }\end{array}$ & 5 \\
\hline $\begin{array}{l}\text { Autoimmune hemolytic anemia } \\
\text { (warm antibodies) }\end{array}$ & Severe & III & 4 \\
\hline \multirow{2}{*}{ Guillain-Barré syndrome } & First-line therapeutic option & I & 1 \\
\hline & After immunoglobulin & III & 3 \\
\hline Thrombotic thrombocytopenic purpura & First-line therapeutic option & I & 3 \\
\hline Myasthenia gravis & First-line therapeutic option & I & 2 \\
\hline Systemic lupus erythematosus & Severe & II & 2 \\
\hline $\begin{array}{l}\text { Autoimmune hemolytic anemia } \\
\text { (cold antibodies) }\end{array}$ & Severe cold agglutinin disease & II & 1 \\
\hline Transverse myelitis & First-line therapeutic option & I & 1 \\
\hline Autoimmune encephalitis & First-line therapeutic option & 1 & 1 \\
\hline Demyelinating encephalitis & Refractoriness & II & 1 \\
\hline Thyroid storm & Severe & II & 1 \\
\hline
\end{tabular}




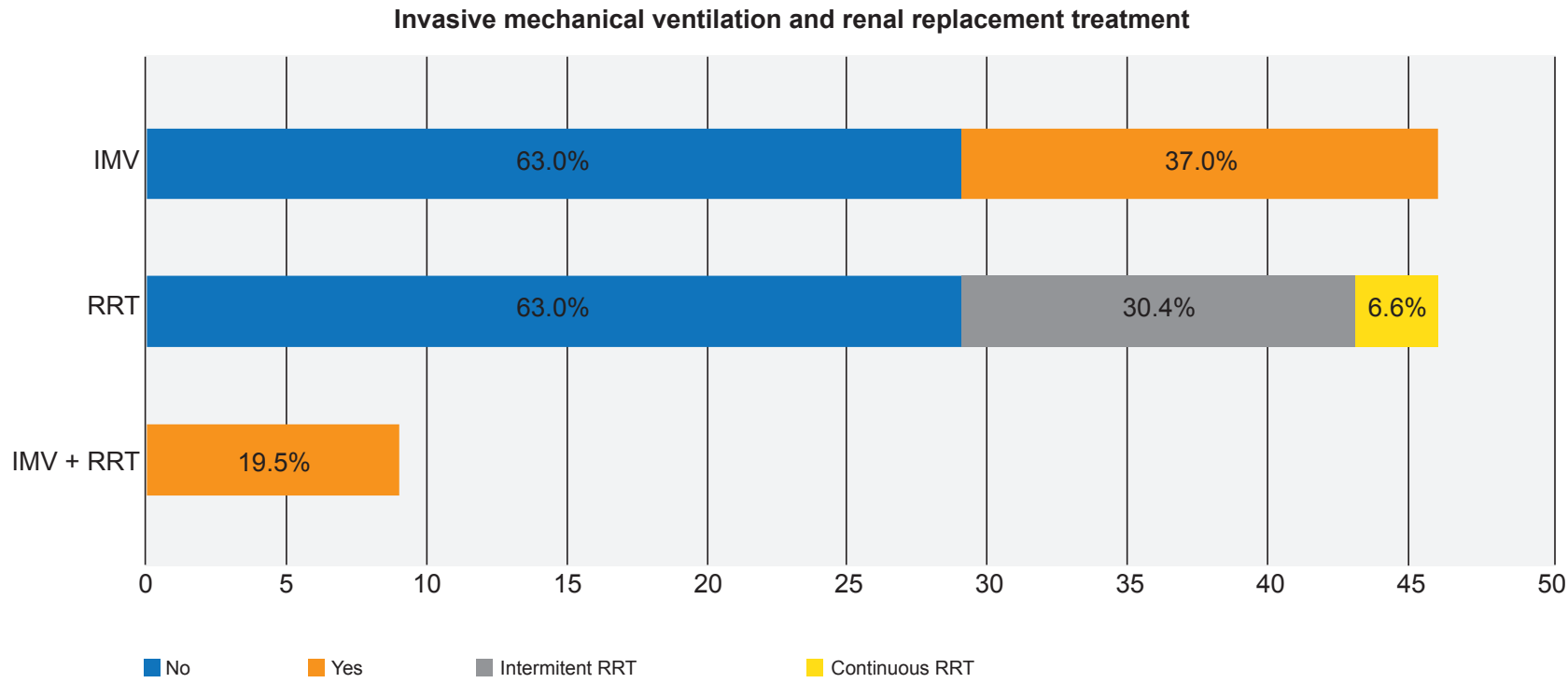

Figure 2 - Description of the percentage of patients that needed invasive mechanical ventilation and renal replacement therapy, in addition to plasmapheresis

IMV: invasive mechanical ventilation; RRT: renal replacement therapy

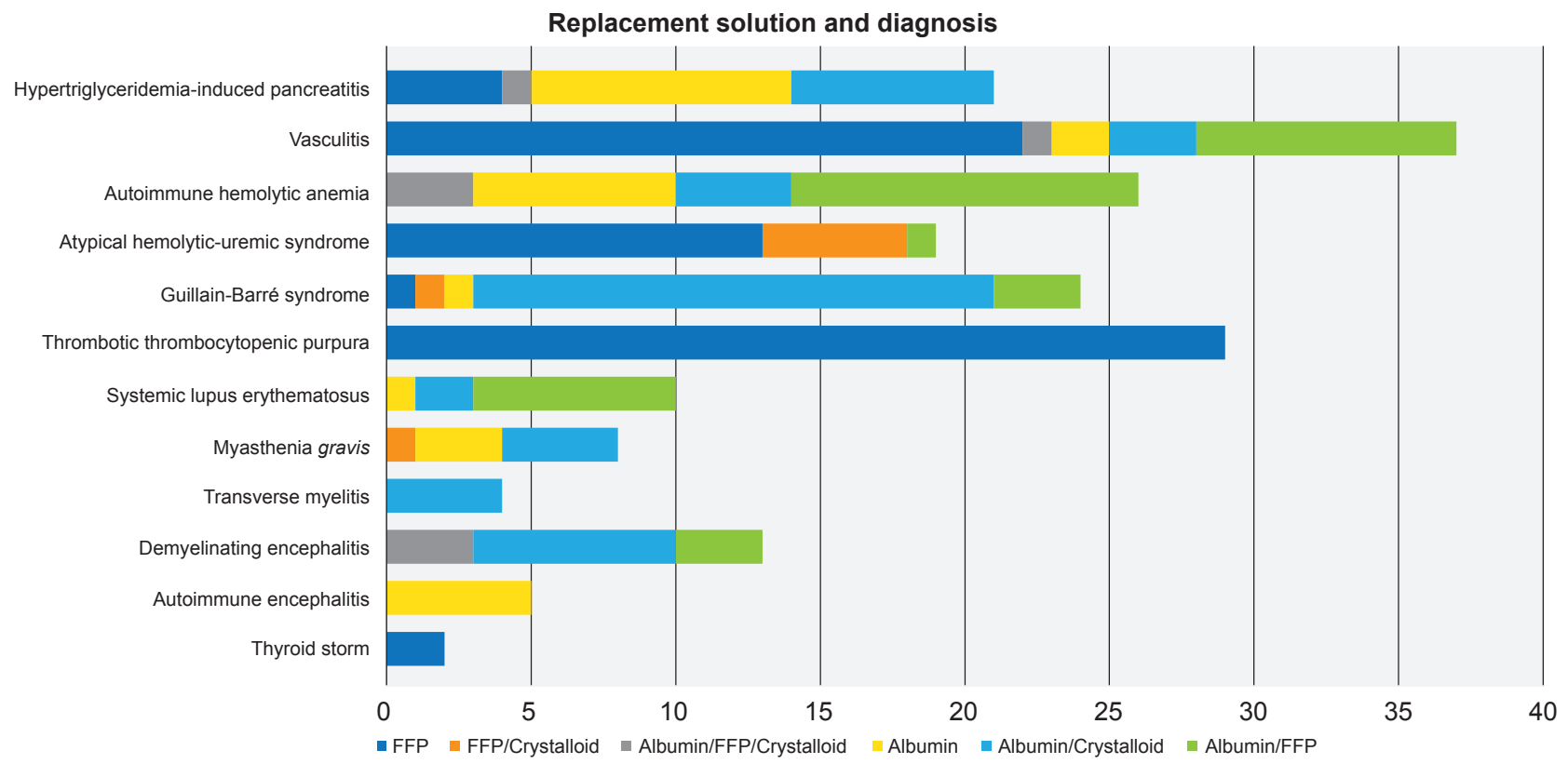

Figure 3 - Replacement solution combinations used for all therapeutic plasmapheresis sessions, according to initial diagnosis TTP: thrombotic thrombocytopenic purpura; Ahus: atypical hemolytic-uremic syndrome; FFP: fresh frozen plasma

14 cases $(82.4 \%)$ and continuous in $3(17.6 \%)$. The most frequent diagnoses were vasculitis $(7 ; 50 \%)$ and aHUS $(4 ;$ $28.5 \%)$. In $19.5 \%(n=9)$ of all cases, IMV and RRT were required. In this group, vasculitis was the most common diagnosis (4; 44.4\%) (Fig. 2).

\section{Characteristics of the plasmapheresis sessions}

The mean replacement volume used was $3,600 \mathrm{ml}$, corresponding mostly to 1 volemic replacement (136; 68.7\%) and 1.5 volemic replacement in $31.3 \%(n=62)$. The mean duration of sessions was 3.4 hours $(2-7)$; however, in many cases $(37 ; 18.6 \%)$, the duration of the PX could not be determined due to a lack of registration in the clinical records. $^{1}$
FFP was the most used replacement solution (68; $34.4 \%)$, followed by the albumin/crystalloid combination (48; $24.2 \%)$, albumin/FFP (38; $19.2 \%)$, albumin $(28 ; 14.1 \%)$, FFP/crystalloid $(7 ; 3.5 \%)$, and albumin/FFP/crystalloid (9; $4.6 \%)$.

When comparing the type of replacement solution with the diagnosis, FFP was the predominant choice in cases of vasculitis, thrombotic thrombocytopenic purpura (TTP), and haemolytic-uremic syndrome. In these cases, replacement with FFP is indicated because its components are indispensable for treatment, such as the replacement of ADAMTS13 in TTP, or also due to the high bleeding risk, such as in alveolar haemorrhage. The only case of thyroid storm was also treated using FFP given the advantage of 
increasing the concentration of thyroglobulin (Fig. 3).

Regarding anticoagulation, heparin was used in $65.2 \%$ ( $n=129$ ) of PX sessions, and regional citrate anticoagulation was used in $28.8 \%(n=57)$. In $6 \%$, it was not possible to ascertain the type of anticoagulation instituted from the clinical records. The dose of heparin (bolus and infusion) did not always reach the recommended value. The mean bolus dose was $2062 \mathrm{UI}$ ( $\min 0$; $\max 5000)$, and the mean infusion dose was $836 \mathrm{UI} / \mathrm{h}(\min 0 ; \max 5000)$.

\section{Number and periodicity of PX sessions}

The following figure represents the number of PX sessions performed, stratified by condition. In most cases, the median of sessions was between five and seven sessions per patient. The diagnosis requiring fewer PX sessions per patient was hypertriglyceridemia-induced pancreatitis (Fig. 4).
The frequency of sessions per patient and condition is more variable. The following figure illustrates this periodicity according to a colour gradient. It is difficult to establish a pattern as it appears that most patients had daily sessions at an early stage, with the interval increasing over time (Fig. 5).

\section{Complications}

\section{a) Interruption of sessions}

Twenty per cent of the PX sessions ( $n=40)$ were interrupted at least once $(30 ; 75 \%)$, and the remainder were discontinued two $(5 ; 12.5 \%)$, three $(4 ; 10 \%)$ or six times $(1$; $2.5 \%$ ).

The technique was interrupted mainly due to filter rupture $(15 ; 37.5 \%)$, elevated transmembrane pressure (TMP) (14; 35\%), and circuit clotting $(7 ; 17.5 \%)$. These events

Number of plasmapheresis sessions

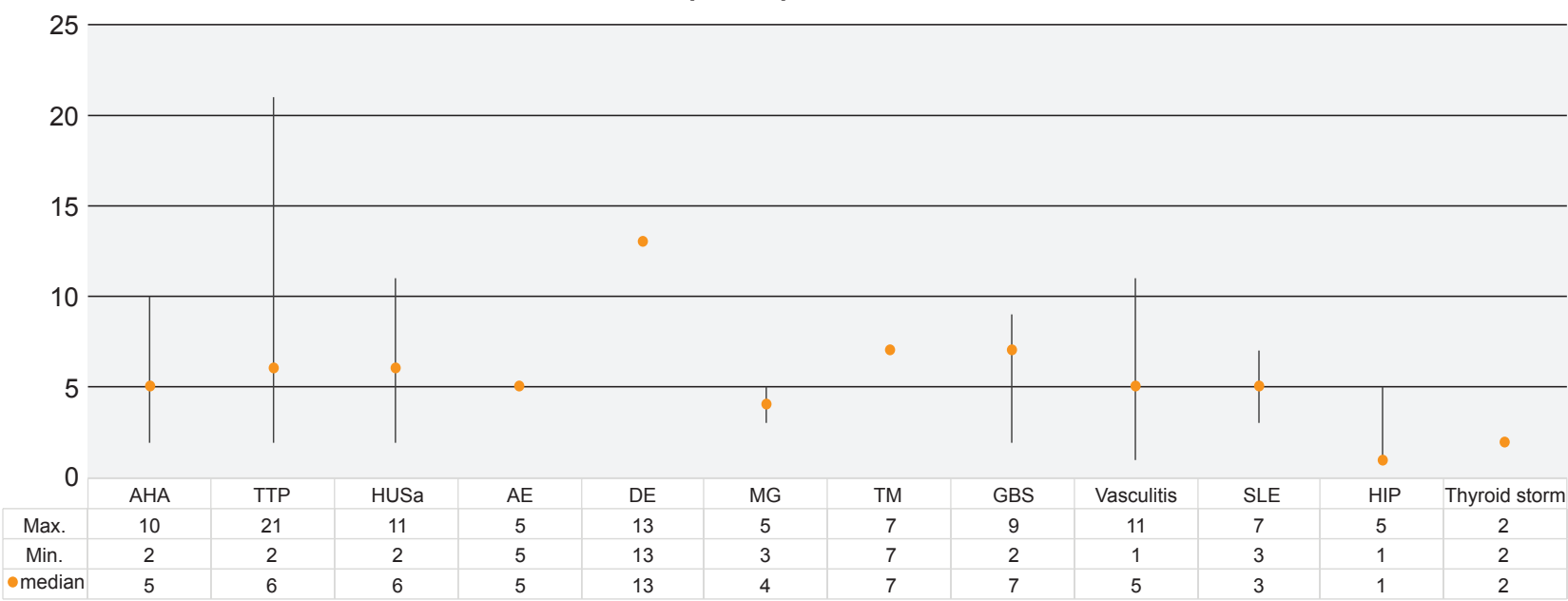

Figure 4 - Graphical representation of the number of therapeutic plasmapheresis sessions required, per each diagnosis AHA: autoimmune hemolytic anemia; TTP: thrombotic thrombocytopenic purpura; aHUS: atypical hemolytic-uremic syndrome; AE: autoimmune encephalitis; DE: demyelinating encephalitis; MG: myasthenia gravis; TM: transverse myelitis; GBS: Guillain-Barré syndrome; SLE: systemic lupus erythematosus; HIP: hypertriglyceridaemia-induced; Max.: maximum; Min.: minimum

\section{Plasmapheresis sessions peridocity}

\section{Days}

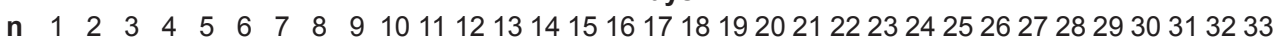

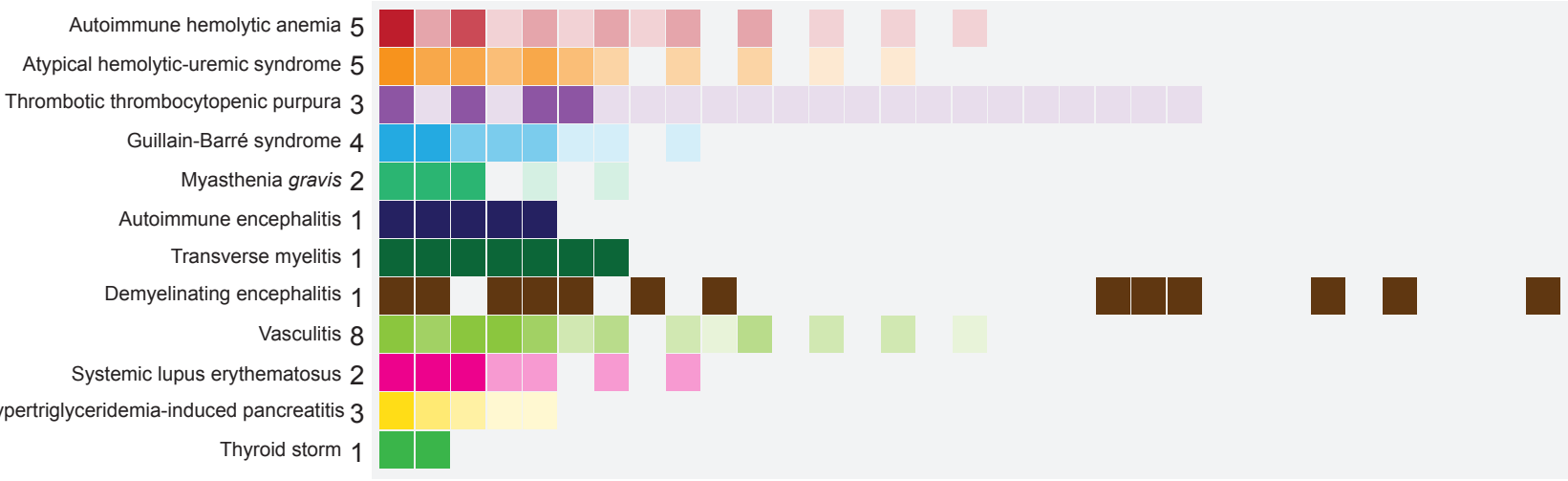

Less patients

Figure 5 - Heatmap of plasmapheresis sessions. For each diagnosis, the intensity of the color for each day is proportional to the number of patients with that diagnosis that have done plasmapheresis in that day.

aHUS: atypical hemolytic-uremic syndrome; TTP: thrombotic thrombocytopenic purpura; SLE: systemic lupus erythematosus 
occurred more frequently when heparin was the anticoagulation chosen. On the other hand, the diagnoses in which sessions were more often interrupted were pancreatitis $(12 ; 30 \%)$ and vasculitis $(8 ; 20 \%)$.

\section{b) Other complications}

Hydroelectrolytic changes, namely hypokalaemia, hypocalcaemia, and metabolic alkalosis, were the most frequent complications $(84 ; 42.4 \%)$, in which $36.9 \%$ had more than one hydroelectrolytic change simultaneously. Hypocalcaemia occurred in $31.3 \%$ of the PX sessions, most often associated with regional citrate anticoagulation $(38.6 \%$ of the citrate sessions had hypocalcaemia, compared with $26.4 \%$ of the heparin sessions). Metabolic alkalosis (27; 13.5\%) was also more frequent with citrate $(36.9 \%$ of sessions with citrate and $4.6 \%$ of sessions with heparin).

Coagulation and platelet disorders occurred in $32.8 \%$ (n = 65), most of them thrombocytopenia $(n=51)$.

We also highlight hypotension $(9 ; 4.5 \%)$, arrhythmias (4; $2 \%)$, acute pulmonary oedema $(2 ; 1 \%)$, hypersensitivity reaction in a PX session with FFP $(1 ; 0.5 \%)$ and problems related with the central venous catheter $(4 ; 2 \%)$.

\section{Outcome}

The ICU LOS was four days (3 - 15), and the hospital LOS was 24 days (12 - 35). Hospital mortality was $21.7 \%$ (n $=10$ ), with $90 \%$ of these patients dying in the ICU. Thirtytwo patients were discharged home $(69.6 \%)$, three $(6.5 \%)$ were transferred to another hospital, and one (2.2\%) was admitted to the National Integrated Continuing Care Network.

\section{DISCUSSION}

$\mathrm{PX}$ is an urgent procedure that can change the clinical course of a disease and reduce morbidity and mortality of critically ill patients. This justifies that $37 \%$ of the patients started the technique before the diagnostic confirmation.

There are several diagnoses and indications for plasmapheresis with different recommendations. ${ }^{1}$

In this study group, plasmapheresis was more frequently performed in patients with hypertriglyceridemia-induced pancreatitis with triglycerides over $1000 \mathrm{mg} / \mathrm{dL}$, although it is a category-III indication (ASFA). ${ }^{11,12}$ In pancreatitis, complications occur more often in the cases of hypertriglyceridemia-induced pancreatitis compared to other causes. ${ }^{13}$ Morbidity and mortality are also higher in that group of patients. ${ }^{14}$ In this case, the rapid and efficient reduction in serum triglyceride levels has a significant impact on clinical outcomes, considering that plasmapheresis is both effective and safe. ${ }^{15}$

Ramírez-Bueno et al demonstrated that $72.7 \%$ of these patients needed only one session of $\mathrm{PX}, 18.2 \%$ received two sessions, and only $9.1 \%$ had three sessions. They obtained an $81 \%$ reduction of the initial level of triglycerides. ${ }^{16}$ Other studies have also shown that a single session of $\mathrm{PX}$ reduces triglyceride levels by $66.3 \%$ to $70 \% .{ }^{15,17}$ An additional exchange increased the triglyceride removal rate to
83.3\%. ${ }^{17}$ In our study, the median of PX sessions in this group of patients was also one session per patient. The benefits of PX in these cases are broader than just the decrease in triglyceridaemia, which also contributes to the removal of excess proteases and the replacement of the protease inhibitors that are consumed. ${ }^{15}$

In pancreatitis, the indicated replacement solution is albumin or crystalloid, and FFP may be associated at the end of the session if there is a high bleeding risk, which was recorded in one session. In most sessions (16; 76.2\%), albumin or crystalloid/albumin was used according to the recommendations.

Anti-neutrophil cytoplasm antibodies (ANCA) vasculitis is a frequent cause of rapidly progressive glomerulonephritis and may be associated with alveolar haemorrhage. The pulmonary-renal syndrome increases mortality significantly. ${ }^{6,18}$

$\mathrm{PX}$ is recommended by international guidelines for the treatment of ANCA vasculitis with pulmonary hemorrhage, based on evidence that shows a faster recovery in most patients, without much impact on kidney function. The efficacy of PX seems to be related with the rapid removal of autoantibodies and proinflammatory mediators that perpetuate the increased permeability of the alveolar-capillary barrier. ${ }^{8}$ However, a recently published randomized controlled trial (PEXIVAS trial) involving 704 patients with severe ANCA associated vasculitis compared the efficacy of plasma exchange with no plasma exchange in terms of mortality or end-stage kidney disease. The use of plasma exchange did not reduce the incidence of death or end-stage kidney disease. ${ }^{19}$

According to the ASFA 2019 guidelines, ${ }^{1}$ alveolar haemorrhage and/or dialysis dependence are indications for $\mathrm{PX}$ (category I). In our study, the main indication was alveolar haemorrhage (87.5\%), also justifying that the FFP was the most used replacement solution (59.5\%). The other combinations of albumin, crystalloid, and FFP were used when the indication was dependent on dialysis and after resolution of alveolar haemorrhage.

Autoimmune haemolytic anaemia may be due to cold or warm antibodies. PX is indicated when the disease is severe or unresponsive to immunosuppression (categories II and III). ${ }^{20,21}$ The recommended replacement solution is albumin. In this study, albumin was used in all sessions, alone or as the main element in a combination with crystalloid or FFP.

Guillain-Barré syndrome is an immuno-mediated, acute inflammatory demyelinating polyneuropathy, which can cause respiratory failure requiring mechanical ventilation.

Recovery is spontaneous; however, recovery can be slow in the most patients with severe disease requiring mechanical ventilation. PX accelerates motor recovery and reduces the number of days of mechanical ventilation. ${ }^{22} \mathrm{PX}$ is recommended as the first-line therapeutic option (category I) and in cases refractory to intravenous immunoglobulin (category III). ${ }^{1}$ Scientific evidence shows that immunoglobulin and PX are equivalent in terms of effectiveness. ${ }^{23,24}$ 
In our study, only one (25\%) patient underwent PX as the first-line therapeutic option. The majority $(75 \%)$ had PX after refractoriness to immunoglobulin. The recommended replacement solution is albumin, used in $91.6 \%$ of the sessions, alone or in combination with crystalloid or FFP.

The atypical haemolytic-uremic syndrome is a disused concept, which classifies a thrombotic microangiopathy (TMA); however, in the absence of better etiological characterization of the TMA type in our patients (mediated by complement, drugs, metabolism, or coagulation), we kept this terminology. ${ }^{25,26}$ Atypical haemolytic-uremic syndrome has a poor prognosis, with a mortality rate around $25 \%$ and a progression to end-stage renal disease in $50 \%$ of cases. ${ }^{27,28}$ PX may achieve full haematological and renal recovery in up to $50 \%$ of cases, although its impact on mortality is not so clear. It is recommended that PX must be started empirically and early in the course of TMA until the definitive diagnosis is clarified. The recommended replacement solution is FFP. ${ }^{28,29}$

TTP is distinguished by the severe deficiency of ADAMTS13, more severe thrombocytopenia, and the more extensive target organ damage, with the exception of the kidney, which is less affected. ${ }^{30}$

Regarding organ support, it is easy to understand that the need for IMV was more frequent in GBS due to ventilatory failure and in ANCA vasculitis due to alveolar haemorrhage.

The need for RRT was more common in aHUS due to the predominant renal impairment, as well as in ANCA vasculitis, regardless of whether the indication for PX was dependent on dialysis or worsened kidney function in patients with pulmonary-renal syndrome.

In most sessions, we chose the replacement solution in agreement with the guidelines. However, we performed some PX sessions with FFP without a clear bleeding risk. We also recorded cases with a combination of albumin and FFP at the end of the session. We believe this decision was aimed at making up for the loss of clotting factors due to the technique. ${ }^{31}$ The depletion of clotting factors is more evident after three to five sessions in the same week, when the replacement solution used is albumin. The bleeding risk can be minimized with the administration of FFP at the end of the PX session. ${ }^{32}$ Despite changes in coagulation, the incidence of bleeding complications is low. In this study, no complications of this nature were registered.

Heparin was the most used type of anticoagulation, probably due to staff experience. Our ICU only started regional anticoagulation with citrate in PX in 2015. Most of the complications with the extracorporeal circuit occurred with heparin, which seems to be related to the infra-therapeutic dose administrated in many cases. ${ }^{33}$

The dose required for anticoagulation with heparin in $\mathrm{PX}$ is higher than that required for other techniques such as RRT, due to the significant extraction of the molecule during PX. This fact, as well as the perception of the risk of coagulation factor depletion during $\mathrm{PX}$, can lead doctors to prescribe doses of heparin closer to those used for RRT, not always reaching the required target.

Citrate ensures a more effective regional anticoagulation of the extracorporeal circuit, minimizing the risk of circuit clotting and systemic effects. ${ }^{33}$ Circuit clotting also occurred in sessions with citrate. This could be attributed to technical issues; however, it was not possible to assess it with the available data. Filtration, when compared with the centrifugation technique, is associated with an increased risk of circuit clotting. Moreover, inadequate pump flow can increase the risk of clotting and elevation of TMP, leading to filter failure. ${ }^{34}$

The interruption of sessions due to filter rupture, clotting or clogging was overcome by replacing the circuit and restarting the PX session. Optimization of both the blood flow rate and the heparin infusion dose were pursued.

Hydroelectrolytic changes were the most frequent complications. Hypokalaemia is partly explained by the low potassium concentration of $5 \%$ albumin $(2 \mathrm{mmoL} / \mathrm{L})$. Potassium chloride was not routinely or prophylactically administered during PX sessions, but hypokalaemia was monitored and corrected with potassium chloride as needed. Metabolic alkalosis occurred mainly when anticoagulation with citrate was used due to its metabolic conversion to bicarbonate. ${ }^{35,36}$ Hypocalcaemia was more frequent with citrate than with heparin, but not as expressively as metabolic alkalosis, probably due to the tight control of calcaemic and correction with continuous infusion of calcium gluconate. Citrate and calcium gluconate infusion rates were titrated according to an established protocol.

Hypotension was corrected with fluids, while arrhythmias and acute pulmonary oedema were treated as usual. A hypersensitivity reaction to FFP was overcome with administration of intravenous antihistamines and corticosteroids and did not lead to interruption of PX.

\section{Limitations}

This is a single-centre retrospective study. Some of the missing data in the electronic health records compromised data collection and a more complete analysis.

\section{CONCLUSION}

$\mathrm{PX}$ is a complex technique that requires specific training. There are several indications, and some are not consensual. Given the urgency of instituting PX, the initial diagnosis is not always confirmed before starting the technique.

Due to its infrequency, the staff experience on PX prescribing and maintenance particularities is not always optimal. This can lead to errors in anticoagulation prescribing, selection of the adequate replacement solution, and frequency of sessions.

For this reason, we consider that training the team and defining a PX action protocol may be important in standardizing the prescribing technique and improving clinical practice. Since complications were frequent but did not affect morbidity or mortality, PX can be considered a safe technique in patients admitted to the ICU. 


\section{AUTHORS CONTRIBUTION}

RF: Design of the study protocol. Data acquisition and registration. Statistics analysis. Draft and critical review of the article. registration. Critical review of the article.

AG: Design of the study protocol. Data acquisition and registration. Statistics analysis. Critical review of the article.

LF, AC, SF: Design of the study protocol. Data acquisition and registration. Critical review of the article.

JC: Design of the study protocol. Database conception and design. Statistics analysis. Critical review of the article.

CMO, AM: Design of the study protocol. Draft and critical review of the article.

\section{PROTECTION OF HUMANS AND ANIMALS}

The authors declare that the procedures were followed according to the regulations established by the Clinical Re-
$A B$ : Design of the study protocol. Data acquisition and

search and Ethics Committee of Hospital Beatriz Ângelo and by the Clinical Research and Ethics Committee and to the Helsinki Declaration of the World Medical Association updated in 2013.

\section{DATA CONFIDENCIALITY}

The authors declare having followed the protocols in use at their working centre regarding patients' data publication.

\section{COMPETING INTERESTS}

The authors have declared that no competing interests exist.

\section{FUNDING SOURCES}

This research received no specific grant from any funding agency in the public, commercial, or not-for-profit sectors.

2013;42:211-4.

REFERENCES
1. Padmanabhan A, Connelly-Smith L, Aqui N, Balogun RA, Klingel R, Meyer E, et al. Guidelines on the Use of Therapeutic Apheresis in Clinical Practice - Evidence-Based Approach from the Writing Committee of the American Society for Apheresis: The Eighth Special Issue. J Clin Apher. 2019;34:171-354

2. Gashti C. Membrane-based therapeutic plasma exchange: a new frontier for nephrologists. Semin Dial. 2016;29:382-90.

3. Kaplan A. Therapeutic plasma exchange: core curriculum 2008. Am J Kidney Dis. 2008;52:1180-96.

4. Hanafusa N. Theoretical basis of pathogenic substance removal during plasmapheresis. Ther Apher Dial. 2011;15:421-30.

5. Daugirdas JT. Handbook of dialysis. $4^{\text {th }}$ ed. Alphen aan den Rijn: Wolters Kluwer Health; 2015.

6. Ward D. Conventional apheresis therapies: a review. J Clin Apher 2011;26:230-8.

7. Paton E, Baldwin IC. Plasma exchange in the intensive care unit: a 10 year retrospective audit. Aust Crit Care. 2014;27:139-44.

8. Geri G, Terrier B, Heshmati F, Moussaoui H, Massot J, Mira JP, et al. Effect of plasma exchange in acute respiratory failure due to antineutrophil cytoplasmic antibody-associated vasculitis. Crit Care. 2018;22:328

9. De Montmollin E, Demeret S, Brulé N, Conrad M, Dailler F, Lerolle N, et al. Anti-N-methyl-D-aspartate receptor encephalitis in adult patients requiring intensive care. Am J Respir Crit Care Med. 2017;195:491-9.

10. González P, García X, Guerra A, Arango J, Delgado H, Uribe C, et al. Experiencia del síndrome de Guillain-Barré en una unidad de cuidados intensivos neurológicos. Neurologia. 2016;31:389-94.

11. Paquette $M$, Bernard S, Hegele RA, Baass A. Chylomicronemia: differences between familial chylomicronemia syndrome and multifactorial chylomicronemia. Atherosclerosis. 2019;283:137-42.

12. Garg R, Rustagi T. Management of hypertriglyceridemia induced acute pancreatitis. Biomed Res Int. 2018;2018:4721357.

13. Adiamah A, Psaltis E, Crook M, Lobo D. A systematic review of the epidemiology, pathophysiology and current management of hyperlipidaemic pancreatitis. Clin Nutr. 2018;37:1810-22.

14. Ewald N. Hypertriglyceridemia-induced acute pancreatitis. Clinical Lipidology. 2013;5:587-94

15. Ewald N, Kloer $H$. Severe hypertriglyceridemia: an indication for apheresis? Atheroscler. 2009;10:S49-52

16. Ramírez-Bueno A, Salazar-Ramírez C, Cota-Delgado F, de la TorrePrados M, Valdivielso P. Plasmapheresis as treatment for hyperlipidemic pancreatitis. Eur J Intern Med. 2014;25:160-3.

17. Yeh J, Chen J, Chiu H. Plasmapheresis for hyperlipidemic pancreatitis. J Clin Apher. 2003:18:181-5.

18. Hruskova Z, Casian A, Konopasek P, Svobodova B, Frausova D, Lanska $\mathrm{V}$, et al. Long-term outcome of severe alveolar haemorrhage in ANCAassociated vasculitis: a retrospective cohort study. Scand J Rheumatol.
19. Walsh M, Merkel PA, Peh CA, Szpirt W, Puéchal X, Fujimoto S, et al. Plasma exchange and glucocorticoids in severe anca-associated vasculitis. N Engl J Med. 2020;382:622-31.

20. Lucchini G, Masera N, Foti G, Assali G, Perseghin P, Biagi E. A lifethreatening paediatric case of acute autoimmune haemolytic anaemia (AlHA) successfully cured by plasma-exchange and combined immunosuppressive treatment. Transfus Apher Sci. 2009;40:115-8.

21. McLeod B. Evidence based therapeutic apheresis in autoimmune and other hemolytic anemias. Curr Opin Hematol. 2007;14:647-54.

22. Chevret S, Rac H, Annane D. Plasma exchange for Guillain-Barré syndrome (Review). Cochrane Database Syst Rev. 2017;2:CD001798.

23. Hughes $R$, Swan $A$, van Doorn P. Intravenous immunoglobulin for GuillainBarré syndrome. Cochrane Database Syst Rev. 2014;2014:CD002063.

24. Freeman C. Evidence-based guideline update: plasmapheresis in neurologic disorders. Neurology. 2011;77:294-300

25. Cataland $\mathrm{S}, \mathrm{Wu} \mathrm{H}$. How I treat: the clinical differentiation and initial treatment of adult patients with atypical hemolytic uremic syndrome. Blood. 2014;123:2478-84.

26. Noris M, Remuzzi G. Atypical hemolytic-uremic syndrome. N Engl J Med. 2009;361:1676-87.

27. Sheerin N, Glover E. Haemolytic uremic syndrome: diagnosis and management. 2019;8:F1000 Faculty Ver-1690

28. Campistol J, Arias M, Ariceta G, Blasco M, Espinosa M, Grinyó J, et al. Diagnóstico y tratamiento. Documento de consenso. Nefrologia. 2015;5:421-47

29. Loirat C, Garnier A, Sellier-Leclerc AL, Kwon T. Plasmatherapy in atypical hemolytic uremic syndrome. Semin Thromb Hemost. 2010;36:673-81.

30. Page E, Kremer Hovinga J, Terrell D, Vesely S, George J. Thrombotic thrombocytopenic purpura: diagnostic criteria, clinical features, and long-term outcomes from 1995 through 2015. Blood Adv. 2017;1:590600 .

31. McLeod B. Plasma and plasma derivatives in therapeutic plasmapheresis. Transfusion. 2012;52:38S-44

32. Szczeklik W, Wawrzycka K, WŁudarczyk A, Sega A, Nowak I, Seczyńska $B$, et al. Complications in patients treated with plasmapheresis in the intensive care unit. Anaesthesiol Intensive Ther. 2013:45:7-13.

33. Lee G, Arepally G. Anticoagulation techniques in apheresis: from heparin to citrate and beyond. J Clin Apher. 2012;27:117-25.

34. Mokrzycki M, Balogun R. Therapeutic apheresis: A review of complications and recommendations for prevention and management. $\mathrm{J}$ Clin Apher. 2011:26:243-8.

35. Kutsogiannis D, Mayers I, Dat W, Chin N, Gibney R. Regional citrate anticoagulation in continuous venovenous hemodiafiltration. Am J Kidney Dis. 2000;35:802-11

36. Schneider A, Journois D, Rimmelé T. Complications of regional citrate anticoagulation: accumulation or overload? Crit Care. 2017;21:1-7. 